\title{
MENÚS MODERNOS: COMIDA, FAMILIA, SALUD Y GÉNERO EN BENGALA COLONIAL
}

\author{
ISHITA BANERJEE \\ El Colegio de México
}

\begin{abstract}
Una lamentable falta de orden invade nuestra Bengala. A esta tierra le falta disciplina y precisión. Esta característica de los bengalíes se refleja particularmente en su comida. La mezcolanza en nuestros banquetes de pescado y postres hechos de leche resulta en un batidillo que va en contra de las reglas de las escrituras y además es dañino para la salud. Mi principal objetivo es salvar la cocina bengalí de este revoltijo y darle orden y disciplina.
\end{abstract}

Así es como Prajñasundari Devi, una de las primeras mujeres autoras de libros de cocina bengalí, hacía publicidad al primer volumen de su libro de recetas vegetarianas publicado en $1900 .^{1}$ ¿Por qué se había vuelto necesario para Prajñasundari, escritora y miembro de la ilustre familia de los Tagore, introducir orden y disciplina en la cocina bengalí a inicios del siglo XX? Claro está que la respuesta no es fácil ni directa. En este ensayo haré un intento preliminar de entender el esfuerzo de Prajñasundari en el contexto del discurso nacionalista de élite con inherente carga de género, pues éste no sólo convertía a la "nueva mujer” en el signo crucial de la diferencia cultural de India, sino que también daba a la salud familiar una importancia clave al hacerla base de una nación saludable. Además, analizaré cómo el discurso sobre la familia, en particular la familia nuclear, surgió imbuido en otro, el discurso de la "nueva" y habilidosa ama de casa como la señora de una familia saludable.

Este artículo fue recibido por la dirección de la revista el 24 de julio de 2014 y aceptado para su publicación el 26 de agosto de 2014.

${ }^{1}$ Prajñasundari Devi, Amish o Niramish Ahar (Comida no vegetariana y vegetariana), Kolkata, Debendranath Bhattacharya, 1900. Véase la nota 39 para mayores detalles. 
Mi propósito no es ofrecer otro análisis del discurso cultural del nacionalismo. Hace varios años, la influyente exposición de Partha Chatterjee acerca de la "resolución nacionalista sobre la cuestión de las mujeres", afirmó que este discurso resolvió su "contradicción constitutiva" de modernizar India siguiendo patrones occidentales y conservar su diferencia cultural como un elemento crucial de "ser indio" gracias a haber reconfigurado a la mujer. ${ }^{2}$ Desde entonces, varios estudios han examinado el lugar y la función de la mujer y las relaciones sociales dentro de la familia como componentes importantes del nacionalismo, retomando, extendiendo o criticando el análisis de Chatterjee. Aquí deseo explorar una dimensión relativamente desconocida del discurso sobre la nación y la familia, esto es, el significado de la salud en la configuración de una nueva familia, "moderna", como la base de una nación saludable, y el papel principal asignado a las señoras de familia como las cuidadoras de la salud y la higiene.

La importancia dada a la comida, en particular a la comida saludable, resultó en la evolución hacia una cocina "moderna", donde hombres y mujeres participaron de manera entusiasta en el proyecto de producir comida nutritiva y apetecible para una familia sana. Un análisis de los modos como hombres y mujeres unieron sus esfuerzos ayudará a desmontar las delicadas nociones de autoridad, educación, familia, comida y salud, y el lugar subyacente de la mujer en tales articulaciones. Esto, a su vez, permitirá una reflexión crítica sobre si la categoría de género puede abrirse para analizar no solamente relaciones sociales enmarcadas por el binario hombre-mujer, sino también aquellas que prevalecen entre hombres frente a hombres y mujeres, y mujeres frente a mujeres y hombres, en distintas posiciones de autoridad dentro de una familia extendida y más allá.

Siguiendo a Mrinalini Sinha, intentaré deducir la "lógica alternativa" del género que se refleja en los manuales domésticos y los libros de cocina escritos por hombres y mujeres, y en los debates sobre nociones de frugalidad y economía domés-

\footnotetext{
${ }^{2}$ Véase de Partha Chatterjee, "The Nationalist Resolution of the Women's Question”, en Kumkum Sangari y Sudesh Vaid (eds.), Recasting Women: Essays in Indian Colonial History, New Brunswick, Rutgers University Press, 1990, pp. 233-253, y Partha Chatterjee, The Nation and its Fragments: Colonial and Postcolonial Histories, Princeton, Princeton University Press, 1993, capítulo 6.
} 
tica que se llevaban a cabo en periódicos publicados por mujeres. Centrarse en la comida y la salud también ofrecerá nuevos entendimientos acerca de la nación en el proceso de ser configurada.

\section{¿Educar a las mujeres?}

Para 1900, se nos ha dicho, el discurso nacionalista en Bengala (y en otras partes de India) había alcanzado una relativa madurez y confianza. El discurso había evolucionado imperceptiblemente desde las primeras décadas del siglo XIX, en el transcurso de las prolongadas luchas entre tradición y reforma social, en las cuales la "condición de las mujeres" era un elemento central. El discurso había ganado confianza y madurez hacia el final del siglo al demarcar el dominio del hogar y la familia como la frontera interna de la nación, la cual se decía que estaba fuera de los límites del Estado colonial. ${ }^{3}$ Los hombres indios se reservaron el derecho único de legislar sobre las mujeres que pertenecían a la familia.

La familia ahora era el núcleo alrededor del cual emergía un gran corpus de literatura sobre cultura y sofisticación, buen gusto y sazón, salud y felicidad, y disciplina y armonía. ${ }^{4}$ La mujer reconstituida, educada pero totalmente dedicada a la familia, la gribalakshmi, diosa Lakshmi de la casa, reinaba sobre este nido de júbilo y belleza; tenía la llave de la salud y la prosperidad de la familia. Lograr esta abrumadora tarea con cuidado, aptitud y precisión requería una elaborada educación y un cuidado meticuloso.

Por lo mismo, no es de sorprender que numerosos manuales domésticos hayan aparecido a partir de 1880 . Todos escritos por hombres, estos manuales buscaban entrenar a la esposa en la difícil tarea de manejar una casa eficientemente, mantener la armonía dentro de la familia, ser la compañera ideal para el esposo educado, poner atención a la salud de la familia, y criar hijos fuertes con comida nutritiva y buena educación.

\footnotetext{
${ }^{3}$ Chatterjee, The Nation and its Fragments, op. cit., capítulo 6.

${ }^{4}$ Pradeep Bose, "Adarsha paribaber adarsha randhanpranali" (Comida ideal para una familia ideal), Anushtup, vol. 32, núm. 1, 1997, pp. 14-40.
} 
Aludo a los manuales para referirme a dos puntos. El primero, y más obvio, es el hecho de que estos manuales indican el surgimiento de un discurso sobre la familia en las últimas dos décadas del siglo XIX, un discurso creado por hombres que insistían en el manejo eficiente de la casa por las mujeres. El segundo punto, de mayor importancia, se refiere a las nociones de género que un análisis crítico de estos manuales puede ofrecer. Aquí tomo de Mrinalini Sinha el llamado crítico a abrir el concepto de género tomando en cuenta la evidencia empírica de las partes no europeas del globo. Sinha nos conmina a leer estos manuales no sólo a través de la visión restrictiva de la noción occidental de género como definitoria de las relaciones sociales entre hombres y mujeres, lectura que nos cierra de antemano la posibilidad de explorar completamente lo distintivo de estos manuales. ${ }^{5}$ En términos de Sinha, el admirable trabajo de Judith Walsh sobre los manuales, algunos de los cuales ha traducido también, está limitado por su perspectiva. Walsh ve los manuales bengalíes a través del lente de la "domesticidad" global y la circulación transnacional de ideas y prácticas de la vida hogareña y familiar, lo que desatiende sus características particulares. ${ }^{6}$

Para empezar, contrario a los manuales producidos en Gran Bretaña y Estados Unidos de América durante el mismo periodo, los cuales fueron todos escritos por mujeres, los autores de los manuales bengalíes fueron hombres. Además, el sujeto de los manuales era muy diferente. Mientras que en Bretaña y Estados Unidos la familia era nuclear, en Bengala (e India) la familia era extendida; consistía en abuelos, padres, hijos, sus esposas, hijas no casadas, tías e hijas viudas o solteras, y algunas veces otros parientes que necesitaban refugio. En tal situación, el lugar de la autoridad estaba repartido entre varios miembros mayores de la familia, incluidas mujeres mayores, contrario a la unidad marital en díada, donde la autoridad de la familia

${ }^{5}$ Mrinalini Sinha, “A Global Perspective on Gender: What's South Asia got to do with It?”, en Ania Loomba y Ritty Lukose, South Asian Feminisms, Durham, Duke University Press, 2012, pp. 362-363.

${ }^{6}$ Judith E. Walsh, Domesticity in Colonial India: What Women Learned when Men Gave them Advice, Lanham, Rowman and Littlefield Publishers, 2004; Judith E. Walsh, How to be the Goddess of your Home: An Anthology of Bengali Domestic Manuals, Nueva Delhi, Yoda Press, 2005. 
recae en los hombros del joven esposo. De acuerdo con Sinha, lo que los manuales bengalíes hicieron fue tratar de mediar un desplazamiento de lugar de la autoridad en la familia extendida, dándole a la figura del joven esposo más importancia de la que tenía.

Los manuales utilizaron lo doméstico como el sitio de construcción de una nueva identidad masculina en oposición a hombres y mujeres mayores, un movimiento que cancela la concepción de género como aquella "que tiene que ver con una construcción binaria del hombre y la mujer". 7 En otras palabras, estos manuales daban a entender una lógica de género distinta, donde los hombres jóvenes (esposos) buscarían establecer su autoridad respecto de familiares mayores, tanto hombres como mujeres, y no únicamente frente a sus jóvenes esposas. ${ }^{8} \mathrm{La}$ asimilación de los manuales bengalíes dentro de una narrativa global deja escapar esta "lógica alternativa" totalmente y hace que se reproduzca el entendimiento estándar de género como una diferencia básica entre hombres y mujeres.

Estos hombres jóvenes intentaban copiar el modelo del hombre inglés que se convertía en un "hombre de familia" tan pronto se casaba y establecía su familia nuclear. Y dado que "los hindúes letrados están dispuestos a imitar las costumbres inglesas, esta práctica, donde es viable, está ganando terreno". ${ }^{9}$ Este intento de cambiar el modelo de la familia extendida con familias nucleares hizo que fuera doblemente importante legitimar su autoridad.

Voy a leer el libro de recetas de Prajñasundari al contrario de esta tendencia, teniendo en cuenta el esfuerzo de los jóvenes esposos, y examinaré cómo los esfuerzos de Prajñasundari se intersecan con las batallas por la autoridad que se libraban a través de textos impresos dentro de las familias. También exploraré por qué la autoridad dentro de la familia se volvió tan importante en aquel tiempo. ¿La preocupación de Prajñasundari por la sistematización, el orden y la eficiencia era similar a aquella reflejada en los manuales domésticos escritos por hombres, o era

${ }^{7}$ Sinha, "A Global Perspective”, op. cit., p. 356.

${ }^{8}$ Ibid., p. 363.

${ }^{9}$ S. C. Bose, The Hindoos, citado en Meredith Borthwick, The Changing Role of Women in Bengal, 1849-1905, Princeton, Princeton University Press, 1984, p. 53. 
diferente? ¿Cuándo y por qué los manuales domésticos fueron complementados por libros y revistas dedicados exclusivamente al arte de cocinar, y qué nos dice esto acerca del discurso doméstico?

\section{Sobre libros de cocina y raíces culinarias}

Pak-pranali, literalmente el proceso de cocinar, una revista mensual dedicada enteramente a la comida y la cocina, empezó a aparecer a partir de 1893. Editada por un brahmán varón, Bipradas Mukhopadhyay, esta revista no sólo intentaba enseñar habilidades culinarias a las mujeres, sino que también las alentaba a aprender nuevos métodos de cocina que les permitirían ahorrar dinero al mismo tiempo que intentaban ricas y sofisticadas recetas en casa. El libro de recetas del mismo nombre, que $\mathrm{Mu}-$ khopadhyay publicó en $1895,{ }^{10}$ puntualizaba la centralidad de la cocina en la cultura integral de India antigua, y lamentaba la falta de cuidado con la que las esposas contemporáneas (kulanarigan, mujeres de buen kula, linaje-ancestros, a quienes fue confiada la continuación de la línea patrilineal del esposo) llevaban a cabo esta tarea auspiciosa y estética. Las mujeres de Bengala del siglo XIX estaban a punto de llevar a la ruina a la familia y la sociedad al tratar la exquisita tarea de cocinar como un quehacer y haciéndolo con total desconsideración. ${ }^{11}$

Mukhopadhyay intentaba devolver a las mujeres su legado y recordarles los beneficios que traería a la sociedad si ellas aprendieran nuevamente los valores de una cocina robusta y los placeres de cocinar. El prefacio acababa con esta nota:

Una comida descontrolada (no balanceada) es de dos tipos: comer poco, es decir comer menos de lo que uno debería; y comer de más, es decir

${ }^{10}$ Bipradas Mukhopadhyay, Pak-pranali, Kolkata, Ananda Publishers, 1987, "Upakramanika" (Prefacio), p. 27. Según Utsa Ray (Culinary Culture in Colonial India: A Cosmopolitan Platter and the Middle Class, Nueva Delhi, Cambridge University Press, 2014, capítulo 2, p. 63), el primer libro de cocina de Bipradas se llamó Soukbin Khadya-Pak y fue publicado en 1889. Fue pronto revisado y reimpreso como Pakpranali. No tuve acceso a Soukhin Khadya-Pak y utilicé la nueva edición publicada en 1987 por Ananda Publishers. Esta edición no hace ninguna referencia a ediciones anteriores.

${ }^{11}$ Mukhopadhyay, Pak-pranali, op. cit., p. 27. 
comer más de lo que uno debería. De los dos, el comer poco causa el deterioro de fuerza, complexión y nutrición [...] y de la mente, la inteligencia y el reflejo de los sentidos [...] La otra, comer de más, da refugio a todo tipo de enfermedades. Por lo tanto, una comida buena y balanceada es el único modo de mantener un cuerpo sano. ${ }^{12}$

Siguiendo esta línea, el primer capítulo del libro (que comprendía 20 páginas) daba instrucciones detalladas sobre cómo mantener la cocina y la bodega limpias e higiénicas y cómo usar el tipo adecuado de combustible a la temperatura apropiada, y aconsejaba el uso de agua limpia y pura; además, describía las cualidades de las variadas ollas y los sartenes de metal utilizados en la cocina. Todo esto lo acompañaba de numerosos detalles sobre los valores nutritivos de diferentes tipos de ingredientes, empezando con los vegetales y el trigo hasta llegar a las especias, así como guías sobre cómo prepararlas para cocinar. El capítulo puntualizaba los beneficios de la mantequilla pura y clarificada hecha de leche de vaca (contra la de leche de búfalo), y finalizaba con discusiones acerca de la carne, los pescados y las aves. Sólo luego de que la mujer casada estaba familiarizada con los intrincados ingredientes y accesorios vitales para cocinar, Bipradas continuaba con las recetas que les ayudarían a mantener viva la cultura culinaria distintiva de India y a mantener el valor de la comida pura y nutritiva.

La preocupación del Pak-pranali por la salud de la familia y los deberes de la buena esposa, así como su intento de educar a las mujeres, lo separaba de sus predecesores. Pakrajeswar, escrito por Bishewar Tarkalankar y publicado en 1831 (reimpreso por los maharajás de Burdwan en 1854), y Byanjan Ratnakar, publicado por el raj Burdwan en 1858, enumeraban recetas elaboradas y extravagantes favorecidas por reyes y príncipes y adecuadas para ellos. El gran número de ingredientes necesarios y el dadivoso uso de grasas saturadas como el ghee, hacían que esos platillos no fueran apropiados para la cocina cotidiana en los hogares ordinarios; de hecho, sus autores dejaron en claro que sus libros no contenían recetas "bengalíes"; más bien fueron tomadas del periodo mogol y estaban orientadas "sobre todo 
hacia platillos no vegetarianos, especialmente de aves silvestres y carnero". ${ }^{13}$

Para Utsa Ray, interesada en analizar la hibridación de la cocina bengalí, la casi total ausencia de cebolla y ajo en las recetas de carnero es un signo de que los lectores de estos libros eran hindúes que todavía no estaban acostumbrados a usar esos condimentos en su comida. ${ }^{14}$ Para defender su argumento, Ray cita al autor de Pakrajeswar, quien dejó en claro que dado que "casi nadie consume cebolla" se había abstenido de incluir ingrediente tan esencial de sus recetas. ${ }^{15}$ Byanjan Ratnakar también siguió el mismo rumbo. Mientras que el punto que Ray marca es válido, sería provechoso preguntarse por qué los libros escritos gracias al patrocinio de príncipes (terratenientes) y que ofrecían recetas dadivosas adecuadas para reyes y príncipes se tomarían la molestia de omitir el ajo y la cebolla. ¿Qué versión de la comida mogola había venido a reemplazar las recetas mughlai en Bengala y cómo había pasado?

El primer libro de recetas en bengalí escrito por una mujer fue publicado en 1879. Titulado Pakprabandha (cerca de la cocina), su publicidad lo describía como un libro bengalí de "recetas comprobadas para la preparación de raros y delicados platillos mahometanos, hindúes y otros". ${ }^{16}$ La autora del libro se nombraba a sí misma "una dama bengalí". No sabemos por qué decidió permanecer en el anonimato. Este libro, como sus predecesores, no mostraba ningún tipo de preocupación por la economía doméstica. Lo que llama la atención es el amplio uso de cebolla y ajo en los platillos “mahometanos”. Utsa Ray lee en este "incremento en el uso de cebolla y ajo para recetas supuestamente escritas para hindúes bengalíes clase medieros”, un cambio en los patrones de la dieta de la clase media de la Bengala colonial. ${ }^{17}$ En mi estimación, el orden en el que aparecen los platillos "delicados y comprobados" en la publicidad es significativo. El hecho de que los platillos "mahometanos" apa-

${ }^{13}$ Ray, Culinary Culture in Colonial India, op. cit., p. 63.

${ }^{14}$ Ibid., p. 64.

${ }^{15}$ Pakrajeswar citado en ibid., p. 64.

${ }^{16}$ Pakprabandha citado en Borthwick, The Changing Role of Women in Bengal, op. cit., p. 213.

${ }^{17}$ Ray, Culinary Culture in Colonial India, op. cit., p. 64. 
rezcan primero indica que la autora, la "dama bengalí”, era posiblemente musulmana con una gran maestría sobre los platillos “mahometanos". Esto explica el libre uso del ajo y la cebolla. Al mismo tiempo, la inclusión de "platillos mahometanos, hindúes y otros" en el mismo libro sugiere que una cocina "moderna", cosmopolita, había evolucionado entre 1850 y 1870.

En otras palabras, es importante investigar la influencia de la cocina mogol o mughlai en la evolución de una cocina bengalí híbrida, que llegó a incluir platillos "coloniales”. Uno se pregunta si acaso los platillos "mahometanos" ofrecidos por la "dama bengalí" se parecían a la cocina mughlai de Pakrajeswar y Byanjan Ratnakar, ahora destinada no sólo a príncipes y reyes, sino también a hogares musulmanes ordinarios que usaban cebolla y ajo. Si el libro tenía un amplio mercado que incluía a hogares hindúes, una posibilidad indicada por el hecho de que el libro fue editado y reimpreso por Pyarimohan Kabibhusan, necesitamos vincular el cambio en los patrones alimentarios de la clase media hindú con cambios en la idea y la noción misma de la cocina, que cada vez más representaba a la cocina "moderna". Es muy desafortunado que "muy poco se sepa de este libro". 18

Para regresar al punto que intentaba marcar, Pakprabandha demuestra que la austeridad en la economía doméstica probablemente no se había vuelto vital en 1870. Por otro lado, un discurso sobre la familia y sobre el rol de las mujeres en ella parece haber emergido entre la parte final de la década de 1850 — cuando se publicó Byanjan Ratnakar y se reimprimió Pakrajeswar - y la primera parte de la década de 1880, cuando los manuales domésticos hicieron su aparición. El discurso acerca de la domesticidad era un brote directo de los debates sobre la reforma social y la condición de las mujeres en las primeras décadas del siglo. Las repetidas referencias a la "pobre condición” de las mujeres hechas por los evangélicos y los liberales británicos, y las afirmaciones de que la prevalencia de tales pobres condiciones era testigo de la naturaleza degradada de la sociedad india y legitimaba el poder colonial, hicieron que los hombres indios reflexionaran sobre las relaciones sociales

${ }^{18}$ Borthwick, The Changing Role of Women in Bengal, op. cit., p. 213. 
y las estructuras de poder dentro de la familia de una forma que no lo habían hecho antes. Si esto hizo que el discurso nacionalista naciente demarcara a la familia como el "núcleo interno" de la nación, la familia fue a su vez configurada de manera novedosa.

La familia de clase media alta, a la cual se estaba idealizando, se enfrentó a una severa crisis en varios ámbitos en las últimas décadas del siglo XIX. La estructura de la familia extendida estaba bajo ataque, pues los hijos "educados" de la familia se iban a las ciudades y pueblos para ejercer sus profesiones, muchas veces llevándose consigo a sus esposas, una decisión que probablemente reflejaba su inclinación a "imitar" costumbres inglesas. Esto generó cambios importantes en el "viejo estilo de vida", los cuales se reflejan en los comentarios incisivos hechos por R. C. Dutt en su novela social Sangsar (mundo social-de vida, traducido al inglés como The Lake of Palms: A Story of Indian Domestic Life, en 1902), publicada en 1855. Dutt menciona que, en los "días de antaño", uno vivía en una comunidad donde la familia era "una unidad indisoluble" bajo la regulación de los ancianos padres. El cambio consistía en instalar casas separadas, lo que significaba "nuevas responsabilidades" para que "los hombres se hicieran cargo" y "nuevas lecciones" para que las mujeres aprendieran, un hecho que constantemente se deja pasar sin examinar o sin reflexionar. Por lo tanto, en lugar de afecto había desorden, y en lugar de paz, discordia. ${ }^{19}$

La elección de palabras de Dutt es reveladora. Los hombres tenían que "tomar nuevas responsabilidades" al establecer su casa (hogar) separada, mientras que las mujeres tenían que “aprender nuevas lecciones”. El rol del joven esposo como el comandante es muy claro; pero la joven esposa tenía que ayudarle tras aprender las nuevas lecciones que él le iba a enseñar. La tendencia a separarse no era la única crisis a la que se enfrentaba la familia extendida; también sufría una severa contracción financiera causada por los crecientes costos de vida y los sueldos bajos que se mantenían estáticos en los puestos abiertos para hombres educados..$^{20}$ Esta contracción hizo que fuera crucial

\footnotetext{
${ }^{19}$ R. C. Dutt, A Lake of Palms, Londres, T. F. Unwin, 1902, p. 92, citado en ibid., p. 53.

${ }^{20}$ Borthwick, The Changing Role of Women in Bengal, op. cit.; Anshu Malhotra,
} 
para las amas de casa manejar la casa de manera austera y eficiente: las lecciones de economía doméstica eran las más importantes que ellas debían aprender.

En la literatura dirigida a las mujeres, era subrayada la necesidad de que las esposas fueran diligentes y no perezosas, lo mismo que el gran valor que se daba a las amas de casa que hacían todas las tareas domésticas "con sus propias manos" (apni hati) puesto que esto generaba prosperidad para la familia. ${ }^{21} \mathrm{En}$ Bengala, el modelo de gribini (ama de casa del griba, hogar) era aquella mujer que "se esforzaba desde la mañana hasta la noche, y encontraba placer en tal trabajo". ${ }^{22}$ Sólo a través del incansable esfuerzo de la diosa del hogar podía la familia ganar fuerza y vigor. Tal familia estaba destinada a cimentar los pilares de la nación.

Los manuales domésticos, tales como Strir sabit kathopokathon (Conversaciones con la esposa), ${ }^{23}$ el primero de su tipo publicado en 1883 (1884) con ocho ediciones hasta 1908, ${ }^{24}$ tenía una sección sobre la salud familiar, en la cual la esposa pedía el consejo del esposo sobre cómo lidiar con problemas de salud comunes, tales como la acidez o el ardor de estómago

Gender, Caste, and Religious Identities: Restructuring Class in Colonial Punjab, Nueva Delhi, Oxford University Press, 2002; Veena Talwar Oldenburg, Dowry Murder: The Imperial Origins of a Cultural Crime, Oxford, Oxford University Press, 2002. Oldenburg en particular muestra cómo en ese tiempo el elevado costo de vida en las parejas con salarios estáticos ocasionó una gran transformación en la naturaleza de la dote en Panjab.

${ }^{21}$ Malhotra (Gender, Caste, and Religious Identities, op. cit., pp. 137-151) cita varios textos reformistas publicados en Panjab, a fines del siglo XIX y principios del xx, que urgían a las mujeres a realizar todas las tareas domésticas ellas mismas, y subrayaban la necesidad de un buen uso del tiempo, lo que haría posible que ellas manejaran el considerable trabajo de casa de manera eficiente.

22 "Subhabibahopalakshe kanyar prati upades" (Consejo a la hija en ocasión de su boda), publicado en Bamabodhini Patrika en octubre de 1887, citado en Borthwick, The Changing Role of Women in Bengal, op. cit., p. 194.

${ }^{23}$ Dhirendranath Pal, Strir sahit kathopokathon, Calcuta, Vaishnav Charan Vasak, 1883-1884. Mis sentidos agradecimientos a Rajat Sur por tomar fotos de la primera edición del manual que se encuentra en la Biblioteca Nacional, Kolkata, y por enviármelas.

${ }^{24} \mathrm{Walsh}$, How to be the Goddess of your Home, op. cit., p. 43. Walsh menciona que a pesar de que el año inglés es 1883 en la primera edición del manual, el año bengalí de publicación es 1290, que se traduce en el año 1884. Los sucesos mencionados en el manual indican que el año es 1884 . Walsh también menciona que éste era el manual más popular del momento, con más de 8000 copias en circulación solamente en la década de 1880. 
y la falta de apetito. La comida y la cocina también eran partes importantes de estos manuales.

Los reformistas del periodo, de diferentes partes de India y con distintos puntos de vista sobre el asunto de la educación de las mujeres, coincidían en un punto: las mujeres necesitaban un tipo de entrenamiento especial. Por lo tanto, la "ciencia doméstica”, que incluía higiene y cocina, figuró en los programas para escuelas femeninas por toda India, al mismo tiempo que los debates y los desacuerdos estallaron sobre otros asuntos. ${ }^{25}$ Ciertamente, para 1930, la salud y la higiene se habían vuelto tan centrales en los programas de "ciencia doméstica" que el libro de texto que iba a ser impartido en las secundarias para el examen de matriculación y aprobado por la Universidad de Calcuta se titulaba Garbasthya Bijñan o Garbnashtya Swastbyatattva (Ciencia doméstica y salud doméstica). ${ }^{26}$

Pak-pranali fue el primer libro de recetas cuya problemática central era la salud de la familia, enfocado en entrenar a jóvenes esposas en las artes culinarias de manera que ayudaran al mantenimiento de una familia robusta. Fue un éxito instantáneo debido a que respondía al tipo de libro necesario para la educación de las mujeres. Bipradas, cabe mencionar, no sólo escribió Pak-pranali; también escribió otros títulos, como Khohar Mayer Gaan (Canciones de la madre de un niño pequeño), Janani Jiban (La vida de madre), Jubatin Jiban (Vida de una joven mujer), libros de texto y "una invitación a la gente a preparar "polao"” (un delicioso y delicado platillo de arroz) en casa (Asun, ghare, ghare polao radbun). Falta ver si todos estos libros o panfletos tenían como objetivo educar o entrenar a las mujeres.

El éxito de Pak-pranali indujo a Bipradas a escribir un detallado texto en dos volúmenes con recetas e instrucciones para preparar dulces en casa. Titulado Mistannapak (Preparación de

${ }^{25}$ Para finales de la década de 1880 , los periódicos y las revistas en Bengala abogaban vehementemente para que la cocina fuera incluida en los programas escolares para niñas. Madhya Bangla Sammilani, una asociación voluntaria, otorgó un premio de cocina en 1895. Véase Borthwick, The Changing Role of Women in Bengal, op. cit., pp. 211-212. Anshu Malhotra confirma esto en Panjab.

${ }^{26}$ Narayan Chandra Bandyopadhay, Garhasthya Bijñan o Garhnashtya Swasthyatattva (revisado por Rai Bahadur Jawaharlal Das), Kolkata, H. Chatterjee and Co. Ltd., 1937. Estoy inmensamente agradecida con Sanjeet Chowdury y Rajat Sur por hacerme llegar este libro. 
dulces), con una edición revisada y aumentada en 1904, el libro hacía del conocimiento de los lectores que el propósito básico del autor era ayudar a las amas de casa a hacer dulces en casa y a no depender de las tiendas. El prefacio argumentaba que los dulces indios eran los mejores y los más puros; sin embargo, dado que los jefes de familia (la palabra usada es grihastha, que significa tanto hombre casado como mujer casada) no saben preparar dulces, dependen de vendedores rapaces, quienes, con el afán de ganar dinero, usan ingredientes adulterados y no ponen atención a la pureza o la limpieza. No les preocupaba que los dulces preparados de manera sucia e impura fueran dañinos para la salud. ${ }^{27}$ Bipradas buscó aliviar esta preocupante situación al enseñar a las amas de casa a preparar dulces en casa. La salud y la comida saludable llegaron a adquirir tal importancia a finales del siglo XIX y principios del xx que incluso los productos permisivos cuyo consumo era ocasional fueron prohibidos a fin de que no pudieran poner en riesgo la salud de la familia.

La atención a la salud de la familia fue complementada con su idealización, como nido de alegría y belleza, el refugio que rejuvenecía al cansado jefe de familia, forzado a trabajar fuera y a encarar sus esfuerzos. La visión de la esposa, calmada y alegre, al final de un agotador día, aliviaba la mente, a la vez que el suave murmullo de los hijos era como música para los oídos. Más importante aún era que la pérdida y el daño que el cuerpo y el alma tenían que sufrir todos los días debido a las presiones del mundo exterior eran más que reparados por la sabrosa comida preparada en la familia (por la esposa)..$^{28}$ Bhudev Mukhopadhyay destaca este punto en su libro Paribarik Prabandha (Ensayo/tratado sobre la familia), pues estaba convencido de que un hogar sin buena comida no era un buen hogar. ${ }^{29}$ Comida, cocina, salud e higiene estaban imbricados en las intrincadas no-

${ }^{27}$ Bipradas Mukhopadhyay, Mistannapak, Kolkata, Sri Gurudas Chattopadhyay, 1904 (edición corregida y aumentada), Prefacio (Upakramanika). Agradezco a Gautam Bhadra por darme acceso a este libro.

${ }^{28}$ Sibnath Sastri, Gribadhrma, Kolkata, Sadharan Braho Samaj, 1881, pp. 6-7, citado en Bose, "Adarsha paribaber adarsha randhanpranali", op. cit., p. 15. Bose da otros ejemplos de la glorificación de la familia por personalidades prominentes de Bengala.

${ }^{29}$ Bhudev Mukhopadhyay, Paribarik Prabandha, Chunchura (Chinsura), Bodhodoy, 1911, p. 193, citado en Bose, "Adarsha paribaber adarsha randhanpranali”, op. cit., p. 14. 
ciones de la cultura del bhadralok (hombres, personas cultas) ${ }^{30}$ y la bhadra paribar (familia culta), que estaba en proceso de demarcación. Y a la diosa de la casa le fue entregada la seria tarea de preparar y producir comida deliciosa y cordial a fin de asegurar el mantenimiento de la buena salud de la familia.

Siguiendo a Mrinalini Sinha, ¿podemos leer una complementariedad entre los manuales domésticos enfocados al entrenamiento de la mujer y estas efusivas expresiones acerca de los placeres de la vida? $\mathrm{Si}$, con los manuales domésticos, los jóvenes esposos intentaban posicionar su autoridad contra los hombres y las mujeres ancianos y llevar las nociones de la familia nuclear a una estructura de familia extendida que estaba bajo presión, en escritos sobre la familia, los padres jóvenes estaban construyendo una familia nuclear idílica, donde la paz y la armonía reinaban y donde el (ahora establecido) patriarca encontraba ayuda y vitalidad. ¿Cómo intervinieron las mujeres en esta cruzada competencia por la autoridad?

\section{La Lakshmi del hogar}

Es tiempo ya de mirar los conceptos y los ideales que intervinieron en las configuraciones del ama de casa como gribalakshmi, la diosa Lakshmi del hogar. Hombres jóvenes y educados combinaron este concepto indio polivalente con nociones idealizadas de la esposa victoriana como la compañera ideal para producir en masa modelos que fueran variados y distintivos.

Lakshmi o Sri, "tal vez la diosa mejor conocida en las tradiciones hindú y jaina", ${ }^{31}$ es adorada ampliamente como la diosa que concede gracia y fortuna. Lakshmi-Sri está íntimamente ligada al dios Vishnu, el conservador del mundo. Alabada como la benefactora que habita en la flor de loto, también ha sido elogiada como la esposa de Vishnu desde que hizo su aparición en

${ }^{30}$ Varios trabajos han discutido el concepto de bhadralok y señalan su composición heterogénea. Véase, por ejemplo, Tithi Bhattacharya, The Sentinels of Culture: Class, Education and the Colonial Intellectual in Bengal (1848-85), Nueva Delhi, Oxford University Press, 2005.

${ }^{31}$ Vasudha Narayanan, "Sri/Giver of Fortune, Bestower of Grace", en John Stratton Hawley y Donna Marie Wulff (eds.), Devi. Goddesses of India, Berkeley-Los Ángeles, University of California Press, 1996, p. 88. 
los Vedas. En los Puranas, Sri emerge como una personalidad diferente, aunque su vínculo con Vishnu no es cortado. Este doble papel de Lakshmi - como una deidad autónoma y auspiciosa, y como consorte de Vishnu- ha sido interpretado de diferentes maneras en diversas ramas del vaishnavismo en India, donde se le han dado varios niveles de importancia a Lakshmi.

Sin entrar en una detallada discusión sobre la genealogía de Lakshmi es importante hacer notar que aparte de ser auspiciosa y autónoma, se concibe a Lakshmi con carácter fuerte y temperamental. Se necesita invocarla con cuidado y adorarla con devoción. Venerarla con prisa y sin la adecuada atención hace que ella se vaya de la casa, lo que causa su ruina. El rol central de Lakshmi como proveedora y alimentadora es reflejado en la manera en que es representada. En India oriental se le adora en forma de una pequeña canasta de mimbre llena de plantas de arroz. Los diseños dibujados en el piso con una pasta de polvo de arroz, cuando se celebra el Lakshmi puja, incluyen una planta de arroz y huellas de Lakshmi. Las huellas son cuidadosamente trazadas de forma que se dirijan hacia dentro, de la puerta del cuarto o casa hacia el lugar de culto. A Lakshmi no se le reza únicamente para que visite la casa y confiera buena suerte, comida, salud y prosperidad; se espera que ella permanezca en la casa para así asegurar su constante bienestar. Lakshmi es chanchala, voluble y móvil, se "queda sólo con aquellos que pueden retenerla". 32

A pesar de que los modelos canónicos de Lakshmi han intentado minar sus atributos heterogéneos para convertirla en una deidad hogareña, cálida y generosa, pero pasiva, obediente y maleable, ${ }^{33}$ la astucia de Lakshmi, su independencia y su fuerza de carácter no han sido borradas. ${ }^{34}$ En Bengala, la idea de Laksh-

${ }^{32}$ Mrinal Pande, Devi: Tales of the Goddess in Our Time, Nueva Delhi, Penguin Books, 1996, p. 73.

${ }^{33}$ Pande (ibid., p. 70) comenta: "cuando las mujeres son bendecidas con las palabras 'Sé como Lakshmi', está implícito que se debe ser cálida, generosa, hogareña, pero pasiva y obediente. Pero la verdadera Lakshmi es todo menos dócil. En su forma arquetípica, ella no solamente es creadora de recursos, también es quien los controla con astucia y engaño cuando es necesario".

${ }^{34}$ En Tamilnadu, por ejemplo, mujeres pobres de distintas extracciones creen que la sakti (fuerza, energía) de la diosa con la que han sido bendecidas las ayuda a aguantar los dolores de parto con entereza. Usualmente se piensa que la diosa es Lakshmi, debido a la cercana conexión de la mujer embarazada con la fortuna. Véase Cecilia 
mi como cuidadora tiene un paralelo cercano en Annapurna, una manifestación de Durga-Parvati, la esposa de Siva. Annapurna es, literalmente, aquel que está lleno de arroz, y marca a la diosa como la proveedora clave de sustento vital. En literatura sobre el hogar o la familia, las mujeres y la comida, los términos gribalakshmi y Annapurna son utilizados con frecuencia para definir a la su-gribini, el ama de casa ideal. Juntas, denotan una mujer exitosa que no sólo cuida bien de su familia, sino que también tiene los recursos y la entereza para alimentar satisfactoriamente a toda su familia y a huéspedes inesperados en todo momento. La unión de Lakshmi con Annapurna crea el ama de casa perfecta: una mujer altamente dotada, pero abnegada, habilidosa y con gran capacidad de resistencia.

Al explorar los diversos significados de la palabra compuesta gribalakshmi, Dipesh Chakrabarty argumentó, en un ensayo escrito hace tres décadas, que gribalakshmi implica nociones de belleza y fortuna, además de la noción de la esposa como la figura crucial en la preservación y la continuación del kula masculino, la línea ancestral vinculada a una concepción míticoreligiosa del tiempo. Esto significa que el concepto-metáfora de gribalakshmi no sólo "escapa y excede" al tiempo burgués, sino que también elude la ecuación con la idea directa de la esposa leal, devota, la pativrata. Esta enrevesada combinación de placer y emoción con la preservación de un linaje masculino permitió a los hombres bengalíes de finales del siglo XIX articular "ideas de una buena vida que asociaron a modelos no autónomos, no burgueses y no seculares de ser persona". ${ }^{35}$

Tras demostrar que los bengalíes usaron simultáneamente dos conceptos contrarios -el de persona individual en la forma de la esposa como la compañera ideal y el de la grihalakshmi como la portadora de la línea ancestral masculina- en las narrativas públicas de la domesticidad, Chakrabarty señala la fractura, falta de unidad, en la historia de lo moderno (bengalíindio).

van Hollen, Birth on the Threshold: Childbirth and Modernity in South India, Berkeley, University of California Press, 2003, pp. 77-79.

${ }^{35}$ Dipesh Chakrabarty, "The Difference-Deferral of a Colonial Modernity: Public Debates on Domesticity in British India”, en David Arnold y David Hardiman (eds.), Subaltern Studies VIII: Essays in Honour of Ranajit Guba, Nueva Delhi, Oxford University Press, 1994, pp. 50-88. 
Mi propósito aquí es algo diferente. Quiero examinar lo que las mujeres pensaban de las connotaciones de Lakshmi y de la esposa ideal para reivindicarse como las verdaderas amas de casa del hogar y la familia. Si los jóvenes esposos competían con los ancianos para establecer su autoridad dentro de la familia extendida, las jóvenes esposas interpretaron y aprehendieron el rol de gribalakshmi para intentar establecer un mínimo de autoridad dentro de la misma estructura familiar, que les otorgaba una muy baja posición en la jerarquía. Al hacer esto, estas mujeres muchas veces colaboraron con sus esposos, pero pronto asumieron ellas mismas el rol de educadoras y cuestionaron los méritos de los hombres en asuntos de comida y cocina.

Aquí es importante destacar un hecho mencionado antes, en el importante trabajo de Meredith Borthwick, donde se afirma que los reformadores hombres brabmo habían tomado la iniciativa para configurar la bhadramabila, la mujer educadaculta, la contraparte femenina del bhadralok, y que las mujeres brabmo fueron las primeras en emular este modelo. ${ }^{36} \mathrm{La}$ familia Tagore, a la cual pertenecía Prajñasundari, no era solamente una prominente familia brabmo, sino que también estaba en la vanguardia de la reforma social; además, desde principios de 1860, algunas mujeres brahmo habían roto con la "costumbre ortodoxa" sobre el vestido, la educación y la purdah, "estaban conscientemente unidas a un cuerpo con una imagen progresista", y eran vistas como pioneras de un nuevo modo de vida que debía ser seguido por otras mujeres que no eran brabmo. ${ }^{37}$

Si esto es cierto, la aceptación del rol del ama de casa por la bhadramabila fue una medida consciente y segura; un rol con el que las mujeres pretendían rebasar la autoridad de los ancianos en la familia extendida, que complementaron y asumieron para rivalizar con sus esposos en la familia nuclear. Si todo el proceso de cocinar era, como decía Bipradas, responsabilidad de la kulanarigan (las mujeres de buen linaje que llevaban la descendencia patrilineal del esposo), entonces no es sorprendente que tales mujeres recrearan, de manera imaginativa, la autonomía y la fortuna asociadas con Lakshmi, junto con un len-

${ }^{36}$ Borthwick, The Changing Role of Women in Bengal, op. cit., p. 54.

${ }^{37}$ Idem. 
guaje de amor, cuidado, nutrición y educación adecuado para establecerse como las diosas de la familia.

\section{Mujeres protagonistas}

Las mujeres de clase media tomaron nota del papel central dado a las habilidades culinarias en la definición de un ama de casa habilidosa y entusiasta. Las revistas de mujeres, que empezaron a aparecer a partir de finales de la década de 1880, introdujeron columnas, casi desde el inicio, para enseñar a las mujeres diferentes formas de cocinar. ${ }^{38}$ Prajñasundari Devi, la editora de la revista familiar Punya, revivió y reinventó recetas de familia y las publicó en su revista. Una compilación de estas recetas dio como resultado los libros Amish o Niramish Abar, comida no vegetariana y vegetariana, de los cuales los dos primeros volúmenes trataban sobre platillos vegetarianos. ${ }^{39}$ Esta obra de múltiples volúmenes al mismo tiempo señalaba la aceptación del rol y el espacio de la mujer dentro del hogar redefinidos, e indicaba el crecimiento de la mujer como educadora. Pronto, las mujeres competirían entre ellas para ocupar este papel.

Las publicaciones de Prajñasundari proveen destellos de lo que las mujeres pensaban acerca de su nuevo rol. En la pequeña presentación que escribió para anunciar el primer volumen de recetas vegetarianas, Prajñasundari subraya que la educación sólo es eficiente cuando es total y no se ve reducida al aprendizaje sin sentido de letras. Aprender a cocinar era una parte integral de esta educación completa. Ciertamente, su propio interés

${ }^{38}$ Ibid., p. 214.

${ }^{39}$ Prajñasundari Devi, Amish o Niramish Ahar (Comida no vegetariana y vegetariana), volumen 1: Comida vegetariana y volumen 2: Comida no vegetariana, Kolkata, Ananda Publishers, 1995. Como se indicó más arriba, el primer volumen, publicado en 1900, fue dedicado a la comida vegetariana (Niramish). El segundo volumen, según la introducción del editor (Ira Ghosh) de la nueva edición de 1995, también fue publicado en 1900. El tercer volumen de comida no vegetariana apareció en 1907 . El cuarto volumen, sobre comida no vegetariana, referido por Kshirodchandra Roychaudhuri (el editor de los dos primeros volúmenes) en su Prefacio al segundo volumen sobre comida vegetariana, nunca fue publicado. La British India Printing Press Works publicó una versión sintetizada de Amish o Niramish Abar en 1914. Y un nuevo volumen sobre pepinillo y chutney fue publicado después. El segundo volumen de la edición de Ananda incluye una sección sobre pepinillo y chutney. 
en cocinar había empezado desde temprana edad gracias al entusiasmo de su madre, Nipamayi, que era artista, y al activo apoyo de su padre, Hemendranath Tagore, quien era químico. Recibió nuevo impulso cuando la responsabilidad de editar la revista familiar, Punya, recayó sobre ella. Su creatividad para escribir poemas para Punya fue complementada con ingeniosas recetas que ella recobraba o inventaba. ${ }^{40} \mathrm{Como}$ el editor Kshirodchandra Roychaudhuri dijo en el prefacio al segundo volumen de recetas vegetarianas, "Prajñasundari había 'descubierto’ el proceso de cocinar como ciencia. Su imaginación y originalidad, así como su precisión científica, eran inigualables; había heredado la precisión científica de su padre y la imaginación poética de su madre". ${ }^{41}$ Como un chef inspirado, Prajñasundari inventó nuevas recetas, dos de las cuales llamó igual que los reformadores sociales, Rammohan (Roy) e (Iswarchandra) Vidyasagar, para rendir tributo a su trabajo.

Una impresionante similitud en el lenguaje y las preocupaciones comparten los libros de Bipradas Mukhopadhyay y Prajñasundari Devi. En las presentaciones que escribió para el primer volumen, Prajñasundari no sólo conminaba a las mujeres a aprender a cocinar, sino que también subrayaba que la precisión y el conocimiento del arte de cocinar eran esenciales para que la comida fuera nutritiva y deliciosa. Los ingredientes muy caros no garantizaban de ninguna manera el éxito de una comida. El gasto sería una pérdida total si la cocinera no había aprendido el "truco" de la buena cocina. ${ }^{42}$ En realidad, la autora decía a los lectores que evitaran el exceso y la extravagancia. La austeridad era lo más importante: Prajñasundari aconsejaba a sus lectores gastar el mínimo de tiempo y dinero al preparar sus recetas ya comprobadas.

El siguiente párrafo de su presentación, con el que empecé este ensayo, ilustraba cómo la mujer colonizada y educada aceptó el discurso de la modernidad. Método y disciplina, decía, eran vitales para el progreso y el perfeccionamiento en cualquier cit.

${ }^{40}$ Ira Ghosh, "Bhumika" (Introducción), en Devi, Amish o Niramish Ahar, op.

${ }^{41}$ Kshirodchandra Roychaudhuri, "Mukhabandha" (Prefacio), en Devi, Amish o Niramish Ahar, op. cit.

${ }^{42}$ Devi, Amish o Niramish Ahar, op. cit., "Bijñapan” (Presentación). 
campo. La comida bengalí carecía casi totalmente de estos elementos. Los pocos recetarios publicados hasta entonces estaban plagados de desorden. Prajñasundari se dispuso a terminar con eso. Sin orden, la columna vertebral de la comida bengalí no podría ser construida jamás. Un amasijo de recetas sin un principio regulador era inútil. Así como un pequeño pero disciplinado ejército era mucho mejor que una banda dispersa de cientos de soldados, un menú balanceado y bien ordenado tenía mucho más valor que una larga lista de recetas mal hechas.

Para demostrar la necesidad de orden y organización, Prajñasundari empezó con el arroz y ascendió en orden a otros platillos en sus dos volúmenes de recetas vegetarianas. Al final, dio una lista de posibles menús, y argumentó que no era una mala idea para los bengalíes seguir el ejemplo de Occidente y tener a mano menús, manuscritos o impresos, encima de las mesas o colgados de la pared en grandes fiestas. Finalmente, la presentación aseguraba que el primer volumen de quinientas páginas apenas si había tocado una pequeña porción de las recetas disponibles; esto demostraba el profundo conocimiento de la autora sobre la cocina. Enseñaba, además, que la cocina vegetariana era por sí misma más que suficiente para saturar las papilas gustativas de los perspicaces y los fastidiosos, lo que era una prueba de su éxito como gran cocinera y como ama de casa ideal.

Prajñasundari criticaba enfática e intencionadamente "el lodazal de pescado y postres hechos de leche" en los festines bengalíes. Su aclamado predecesor, Bipradas, no sólo había ofrecido consejos sobre una cocina adecuada, pura y saludable, y proveído de numerosas recetas que incluían platillos hindúes, musulmanes y cristianos de diferentes partes de India, sino que también proporcionó menús de muestra para banquetes en el apéndice de Pak-pranali. En estos menús encontramos la prohibición de mezclar muchos platillos de pescado y postres hechos de leche. Prajñasundari necesitaba remarcar su superioridad al señalar que sus menús eran no sólo más novedosos, sino también mejores para la salud. Mostró mayor conocimiento científico al empezar con los platillos de arroz, la base de la alimentación de Bengala, en lugar de iniciar con shuktani (un plato de varios vegetales con pasta de mostaza, a veces amargo debido a que le agregaban melón amargo) y otros platos de vegetales, 
considerados como "platillos acompañantes" en la comida bengalí, como Bipradas lo había hecho.

Hay un interesante forcejeo aquí. Prajñasundari está claramente compitiendo con sus contrapartes masculinas que intentaban entrenar a las mujeres en el arte de cocinar, pero ella asociada con los hombres de su propia familia. Ciertamente, como menciona su nieta, Ira Ghosh, en la introducción a la nueva edición, el interés de Prajñasundari en la cocina y sus experimentos con nuevas recetas recibieron impulso después de que se casó, a una edad temprana, con el literato asamés (que era un estudiante al momento de casarse) Lakshminath Bejbarua, quien amaba comer. Prajñasundari sirvió sus nuevos platillos a su esposo, y anotó las recetas en su diario sólo hasta que recibieron la aprobación de aquél. Además, el esposo fue fundamental para la publicación de las recetas. De cierta manera, Prajñasundari y Lakshminath interpretaban el papel de la familia nuclear perfecta, donde las parejas eran iguales y verdaderos compañeros. También en la vida real, Prajñasundari acompañó a su esposo a los lugares en los que él trabajaba, y no se quedó esperándolo junto a la familia extendida.

Las afirmaciones de Prajñasundari acerca de que ella tenía más conocimiento, habilidad y precisión sobre la comida y la cocina, están basadas en el discurso masculino de los beneficios de la "verdadera educación" para la nueva mujer. Prajñasundari personificaba todas las virtudes que la verdadera y completa educación confería a las mujeres; vindicaba la necesidad de educación para las mujeres al mostrar la falsedad de los comentarios que decían que las mujeres educadas tenían por hábito descuidar los deberes domésticos. Solamente una educación incompleta y parcial, incorrectamente impartida por esposos a medio educar, hacía que las mujeres se alejaran de sus responsabilidades naturales. Esto transformaba a la familia-hogar en un campo de cremación: la morada de Alakshmi, la contraparte negativa de Lakshmi. En contraste, salud y riqueza, felicidad y belleza, reinaban en el hogar de la sugribini, la diosa Lakshmi.

El primer volumen de cocina vegetariana aconsejaba a las mujeres cómo lidiar con sirvientes y cocineros, enseñándoles a delegar tareas sin entregar la responsabilidad. Esto iba contra el ethos de manuales domésticos que conminaban a la mujer a 
hacer todo ella misma. Además, Prajñasundari instruía a los esposos a pedir cuentas claras a sus sirvientes en asuntos de dinero gastado en comida, y advertía de la ruina financiera que podían sufrir si evadían esta responsabilidad. El esposo y la esposa tenían que estar siempre vigilantes y mantener el control si querían que su familia floreciera.

\section{Lucha territorial}

La economía doméstica era un elemento clave en los libros de cocina de Prajñasundari. El primer capítulo del primer volumen de comida vegetariana, titulado sadharan katha, asuntos mundanos, hablaba de la necesidad de comida sabrosa e insistía en lo difícil que era conseguirla. La buena comida no es fácil de preparar; requiere conocimiento y dotes artísticas. Estos dos elementos eran cada vez más escasos dado que las mujeres de familia estaban virtualmente cediendo el trabajo de cocinar a los sirvientes. Era ilusorio esperar que un empleado pobre e inculto se dedicaría a la tarea con la agilidad del ama de casa. Su único objetivo era terminar con la tarea tan fácil y rápidamente como fuera posible. La falta de limpieza y de sabor era el resultado; por lo tanto, se urgía al ama de casa a pedir ayuda al sirviente, pero jamás delegarle la tarea de cocinar.

Un ama de casa consumada era aquella que podía hacer el mejor uso de los ingredientes, ya fueran cáscaras de papa o semillas de patol (calabacita puntiaguda). ${ }^{43}$ No sólo había que tener mucho cuidado para evitar desperdicios, sino también saber cocinar para mantener el valor nutricional de los ingredientes. Juntos, tal conocimiento e ingenio permitían a Prajñasundari mantener su afirmación de que como educadora era mejor que sus contrapartes masculinos, aunque esto la metió en problemas con sus competidoras femeninas.

El desafío vino de Antahpur (Espacio interior), una revista dirigida enteramente por mujeres que empezó a publicarse desde 1897. Antes de entrar a la controversia, vale la pena citar un extracto del editorial del segundo número del primer volumen.

${ }^{43}$ Ghosh, "Bhumika", op. cit. 
Antahpur es la parte de la casa donde la mujer vive. Es un espacio separado e independiente, lejos de la conmoción y actividad del mundo exterior, pero no es por esto un lugar insignificante. Es la fábrica que provee de energía vital a las arterias de la sociedad, introduciendo fe y moral dentro de ella, y sirve para revitalizar y perfeccionar cada aspecto de la sociedad. Es el lugar de meditación para la mujer.

La sociedad es un mero reflejo del antahpur. El progreso moral de la sociedad depende totalmente de los sólidos cimientos del dharma (fe) y la moralidad en la familia. Antahpur es donde el carácter moral de la humanidad toma forma. El niño recibe las primeras lecciones en el regazo de la madre; esto ayuda a su realización como individuo. El niño es el elemento principal de la nación futura. Mientras antahpur sea fuerte, la sociedad permanecerá fortalecida. La misión de una mujer en la vida es hacer de antahpur un lugar exquisito. Antahpur es el corazón del cuerpo social. ${ }^{44}$

Así es como Banalata Devi, la editora de Antahpur, explicaba la importancia del término a sus lectoras, y racionalizaba su elección como título para la revista. Por una parte, el editorial parece hacer eco del discurso masculino nacionalista contemporáneo, el cual redefinía el papel y el espacio de la "nueva" mujer, ubicándolo firmemente dentro del hogar, para cargar a la mujer con la responsabilidad de administrarlo eficientemente. Por otro lado, el editorial implica una aceptación resoluta de este rol por la mujer como un sujeto-agente consciente; refleja la percepción de una mujer de clase media educada sobre su importante posición en el proyecto de crear una nación moderna: sobre configurar un interior pacífico, la familia, como el núcleo y el elemento vital de la sociedad, y como contraparte del exterior caótico. La vitalidad y moralidad del organismo social dependía totalmente del cuidado y la educación provistos dentro de la familia por el ama de casa exitosa.

Esta valorización del antahpur era similar, aunque diferente de los discursos efusivos de hombres educados sobre la paz, la calma, el vigor (la salud) y el mundo interior que la familia ofrecía. En el mundo interior creado por mujeres, los hombres tenían acceso limitado; hacia el final del siglo XIX las muje-

${ }^{44}$ Antahpur, vol. 1, núm. 2, febrero-marzo, 1897. Desde 1900, el título se ponía en bengalí e inglés, y Banalata Devi agregó "editado y escrito por damas exclusivamente” después del título. 
res educadas habían redefinido dentro del mundo interior sus propios términos y habían marcado sus fronteras.

La alimentación nutritiva era un elemento clave de las responsabilidades de antahpur. En consonancia con esto, la revista incluyó desde el principio recetas de comida y artículos sobre comida y cocina. Sobre esto, las mujeres libraron batallas para el mejor conocimiento y dominio del delicado arte de cocinar.

En la receta para una mermelada de guayaba, publicada en el primer número del volumen $4,{ }^{45}$ la autora aconsejaba desechar los restos de la guayaba una vez se le hubiera extraído la pulpa. Prajñasundari, la siempre alerta sugribini, se sintió ofendida: escribió una carta a la revista donde decía que en lugar de ser desechada, el resto de la guayaba podía ser usada para preparar otro plato, el morobba (una especie de digestivo hecho de frutas o vegetales).

La respuesta de Antahpur no se hizo esperar. En el tercer número de ese mismo volumen, ${ }^{46}$ una "lectora de Antahpur" declaró airadamente que la crítica de Prajñasundari carecía de contenido, pues era insensato meter otro platillo, menor, en la receta del platillo principal. La inclusión de otra receta habría causado confusión, especialmente entre las novatas. $\mathrm{Al}$ sugerir que otro platillo debía haber sido mencionado, Prajñasundari subrayaba su "ignorancia" en cuestiones del hogar. No era de sorprender, dijeron, puesto que eran hombres quienes más contribuían con artículos a la revista de Prajñasundari. Por su parte, Antahpur era dirigida totalmente por mujeres, y por mujeres que eran exitosas amas de casa, buenas cocineras y que habían probado y preparado todos los platillos antes de publicar sus recetas. La credibilidad y confiabilidad de tales recetas era evidente: habían sido cocinadas y servidas por las amas de casa en sus propias casas.

\footnotetext{
${ }^{45}$ Antahpur, vol. 4, núm. 1, enero-febrero, 1900.

${ }^{46}$ Antahpur, vol. 4, núm. 3, marzo-abril, 1900.
} 


\section{“QQué tiene que ver el género?”}

¿Habría habido un giro drástico si se hubiera completado el ciclo? La editora y las lectoras de una revista manejada enteramente por mujeres estaban amonestando a otra experta educadora y cocinera por apoyarse en hombres para cuestiones de tareas domésticas y para editar una revista con su ayuda. Si los hombres habían configurado la frontera interior de la nación y habían puesto a las mujeres dentro, ahora las mujeres habían hecho de esta esfera interior su propio dominio. Aquellas parecidas a Prajñasundari eran reprendidas por involucrar a hombres en tareas que legítimamente pertenecían a las mujeres.

¿Significa esto que estamos retrocediendo a la conceptualización "estándar" de género al pensar en el binario de hombres y mujeres? Los intrincados procesos que he intentado rastrear nos cuentan una historia diferente. Estos procesos muestran la enrevesada y cercana evolución de la familia moderna, y la cocina moderna y saludable, tomados como elementos clave de la sociedad y la nación en el siglo XIX. En ambos procesos, las mujeres tomaron el papel central gracias a esfuerzos divergentes de hombres y mujeres. En uno, la familia nuclear lentamente desplazó a la familia extendida a través de la participación activa de los esposos jóvenes, quienes intentaban ganar más autoridad frente a sus mayores, hombres y mujeres, para después establecer sus propios hogares. Las esposas jóvenes fueron muchas veces las cómplices de sus esposos en esta batalla generacional; sin embargo, una vez que la familia nuclear se convirtió en la norma, al menos discursivamente, las mujeres de clase media tomaron la iniciativa al reivindicar su supremacía sobre la familia. En otro proceso coincidente, los hombres que intentaron entrenar a las mujeres en el arte de la cocina y la domesticidad en la primera mitad del siglo xIx fueron desafiados por mujeres que demandaban autoridad exclusiva sobre el entrenamiento de las amas de casa. La centralidad de la familia, la salud, el cuidado y la cocina en ambos discursos permitió a mujeres habilidosas establecer control sobre el dominio reservado para ellas. Al mismo tiempo, en estos conflictos cruzados, esposos y esposas actuaron muchas veces como un equipo para establecer sus demandas contra familiares mayores, y contra hombres y mujeres 
externos a la familia. En otras palabras, no hay una simple historia de hombres contra mujeres trabados en constante combate; más bien, hay historias matizadas de identidades masculinas y femeninas siendo construidas de manera contingente en relación con hombres y mujeres, y mujeres y hombres, ancianos y rivales, dentro y fuera de la familia. En este recuento, el género emerge como una categoría fluida y cambiante que encarna muchos significados, y se desestructura y reestructura de distintas maneras. Si podemos deducir una lógica alternativa en la forma en que los esposos jóvenes y los padres cooptaron y colaboraron con sus parejas para reclamar mayor autoridad de los mayores en una familia extendida, y las mujeres internalizaron y se apropiaron del discurso masculino para legitimar su autoridad suprema sobre el "hogar" - un espacio interno donde vivían en armonía con sus parejas- y se juntaron para demarcar un "afuera" a fin de excluir a los hombres y, eventualmente, a las mujeres rivales, podemos empezar a "repensar" el género a la luz de esta "ubicación distinta". ${ }^{47}$

Dirección institucional de la autora:

Centro de Estudios de Asia y África

El Colegio de México

Camino al Ajusco 20

Pedregal de Sta. Teresa, 10740

México, D.F.

ibanerje@colmex.mx

\section{Bibliografía}

Antahpur, vol. 1, núm. 2, febrero-marzo, 1897; vol. 4, núm. 1, enerofebrero, 1900; y vol. 4, núm. 3, marzo-abril, 1900.

BANDYOPADHAY, Narayan Chandra, Garhastbya Bijnan o Garbnashtya Swastbyatattva (revisado por Rai Bahadur Jawaharlal Das), Kolkata, H. Chatterjee and Co. Ltd., 1937.

Bhattacharya, Tithi, The Sentinels of Culture: Class, Education and the Colonial Intellectual in Bengal (1848-85), Nueva Delhi, Oxford University Press, 2005.

${ }^{47}$ Sinha, “A Global Perspective”, op. cit., p. 356. 
BORTHWICK, Meredith, The Changing Role of Women in Bengal, 18491905, Princeton, Princeton University Press, 1984.

Bose, Pradeep, "Adarsha paribaber adarsha randhanpranali”, Anushtup, vol. 32, núm. 1, 1997, pp. 14-40.

Chakrabarty, Dipesh, "The Difference-Deferral of a Colonial Modernity: Public Debates on Domesticity in British India”, en David Arnold y David Hardiman (eds.), Subaltern Studies VIII: Essays in Honour of Ranajit Guba, Nueva Delhi, Oxford University Press, 1994, pp. 50-88.

Chatterjee, Partha, "The Nationalist Resolution of the Women's Question”, en Kumkum Sangari y Sudesh Vaid (eds.), Recasting Women: Essays in Indian Colonial History, New Brunswick, Rutgers University Press, 1990, pp. 233-253.

Chatterjee, Partha, The Nation and its Fragments: Colonial and Postcolonial Histories, Princeton, Princeton University Press, 1993.

Devi, Prajñasundari, Amish o Niramish Ahar, Kolkata, Ananda Publishers, 1995.

Devi, Prajñasundari, Amish o Niramish Ahar, Kolkata, Debendranath Bhattacharya, 1900.

Grosh, Ira, "Bhumika", en Prajñasundari Devi, Amish o Niramish Abar, Kolkata, Ananda Publishers, 1995.

Malhotra, Anshu, Gender, Caste, and Religious Identities: Restructuring Class in Colonial Punjab, Nueva Delhi, Oxford University Press, 2002.

Mukhopadhyay, Bipradas, Mistannapak, Kolkata, Sri Gurudas Chattopadhyay, 1904.

MukhopadHyay, Bipradas, Pak-pranali, Kolkata, Ananda Publishers, 1987.

NARAyanan, Vasudha, "Sri/Giver of Fortune, Bestower of Grace", en John Stratton Hawley y Donna Marie Wulff (eds.), Devi. Goddesses of India, Berkeley-Los Ángeles, University of California Press, 1996, pp. 87-108.

Oldenburg, Veena Talwar, Dowry Murder: The Imperial Origins of a Cultural Crime, Oxford, Oxford University Press, 2002.

PaL, Dhirendranath, Strir sabit kathopokathon, Calcuta, Vaishnav Charan Vasak, 1883-1884.

Pande, Mrinal, Devi: Tales of the Goddess in Our Time, Nueva Delhi, Penguin Books, 1996.

RAY, Utsa, Culinary Culture in Colonial India: A Cosmopolitan Platter and the Middle Class, Nueva Delhi, Cambridge University Press, 2014.

ROYCHAUDHURI, Kshirodchandra, "Mukhabandha”, en Prajñasunda- 
ri Devi, Amish o Niramish Ahar, Kolkata, Ananda Publishers, 1995.

SINHA, Mrinalini, “A Global Perspective on Gender: What's South Asia got to do with It?”, en Ania Loomba y Ritty Lukose, South Asian Feminisms, Durham, Duke University Press, 2012, pp. 362-363.

VAn Hollen, Cecilia, Birth on the Threshold: Childbirth and Modernity in South India, Berkeley, University of California Press, 2003.

Walsh, Judith E., Domesticity in Colonial India: What Women Learned when Men Gave them Advice, Lanham, Rowman and Littlefield Publishers, 2004.

Walsh, Judith E., How to be the Goddess of your Home: An Anthology of Bengali Domestic Manuals, Nueva Delhi, Yoda Press, 2005. 